\title{
Performance evaluation of Fenton based processes in reducing COD of the petroleum effluents using the waste of steel slag
}

Fatemeh EtemadiasI

Shahid Chamran University of Ahvaz

Parvaneh Tishehzan ( $\nabla$ ptishehzan@yahoo.com )

Shahid Chamran University of Ahvaz https://orcid.org/0000-0002-5283-1047

Seyed Mahmood Kashefipour

Shahid Chamran University of Ahvaz

Nematolah Jaafarzadeh Haaghighifard

Ahvaz Jondishapour University of Medical Sciences

\section{Research Article}

Keywords: EF, PF, PEF, COD, Taguchi, Steel slag, Petroleum effluent

Posted Date: June 13th, 2022

DOI: https://doi.org/10.21203/rs.3.rs-1033579/v2

License: (c) (i) This work is licensed under a Creative Commons Attribution 4.0 International License.

Read Full License 
3 Fatemeh Etemadias ${ }^{1}$, Parvaneh Tishehzan ${ }^{* 2}$,Seyed Mahmood Kashefipour ${ }^{3}$, Nematolah Jaafarzadeh Haaghighifard ${ }^{4}$

4

6

\section{Abstract}

Petroleum effluents pollution is an important challenge for many countries. The aim of this study was to investigate the efficiency of Fenton, Photo-Fenton (PF), Electro-Fenton (EF) and Photo-Electro-Fenton (PEF) processes in reducing chemical oxygen demand (COD) of desalination unit effluent using steel slag as catalyst, cathode and anode. For achieving this goal the experimental design by Taguchi method using Mintab18 software was used. The desired variables include $\mathrm{pH}(3,5$ and 7$)$, hydrogen peroxide $(5,10$ and $15 \mathrm{mmol} / \mathrm{l})$, contact time (30,60 and 90 min), catalyst $(5,7.5$ and $10 \mathrm{~g} / \mathrm{L})$, radiant intensity $(16,24$ and $32 \mathrm{~W})$ and voltage $(5,15$ and $30 \mathrm{~V})$. In order to perform the experiments, the pilot was made using UV-C lamps (wavelengths of 200-280 nm) each with a power of $8 \mathrm{~W}$ and an AC power supply of $0-30 \mathrm{~V}$ in the range of 0-2 A. According to the results, PEF process under $\mathrm{pH}=7,10 \mathrm{mmol} / \mathrm{l}$ hydrogen peroxide, catalyst content of $5 \mathrm{~g} / \mathrm{L}$, radiant intensity of $24 \mathrm{~W}$ and voltage of $5 \mathrm{~V}$ for 90 min, provides the highest COD removal rate (98.7\%). The present study showed that following the combined process of PEF, EF, PF and Fenton processes have a high potential in reducing COD using steel slag.

Keywords: EF, PF, PEF, COD, Taguchi, Steel slag, Petroleum effluent

\section{Introduction}

Treatment of industrial wastewater containing toxic and hazardous substances is one of the world's environmental challenges. Various methods are used to treat industrial wastewater, including physical, chemical and biological processes. Technologies such as adsorption or coagulation, transfer the contaminants from one phase to another and the contaminant is not completely eliminated (1). In recent years, among all chemical treatment processes, advanced oxidation process (AOP) methods have been widely studied due to their effective efficiency in removing various contaminants, especially stable organic contaminants (2).

\footnotetext{
1 M.Sc. Student of Environmental Engineering, Environmental Engineering Department, Faculty of Water and Environmental Engineering, Shahid Chamran University of Ahvaz, Ahvaz, Iran. Postal Code: 6135743311., Email:Fatima_etemadi@yahoo.com, fatemeh-etemadias1@stu.scu.ac.ir

$2 *$ corresponding author: Assistant Professor, Environmental Engineering Department,, Faculty of Water and Environmental Engineering, Shahid Chamran University of Ahvaz, Ahvaz, Iran. Postal Code: 6135743311, Email: ptishehzan@yahoo.com, partishehzan@scu.ac.ir, Phone Number : 009809163050638 , Fax Number : 00986133365670

3 Professor, Environmental Engineering Department, Faculty of Water and Environmental Engineering, Shahid Chamran University of Ahvaz, Ahvaz, Iran. Postal Code: 6135743311, Email: kashefipour@ scu.ac.ir

${ }^{4}$ Professor, Environmental Technologies Research Center, Ahvaz Jundishapur University of Medical Sciences , Ahvaz , Iran, Email: n.jaafarzade@yahoo.com,Jaafarzadeh-n@ajums.ac.ir
} 
Advanced oxidation was first used for water treatment in $1980(3,4)$. AOP processes are based on processes that produce an appropriate amount of active radicals such as hydroxyl radical $\left(\mathrm{OH}^{\bullet}\right)$, radical $\left(\mathrm{SO}_{4}^{--}\right)$and oxygen radical $\left(0^{\bullet}\right)(5-7)$.

27 Since hydroxyl radicals have high oxidizing power $\left(E^{\bullet}=2.8 \mathrm{~V}\right)$, they remove most contaminants (especially organic contaminants). These methods are more capable of treating toxic contaminants, usually do not have the problem of surplus disposition and waste, are performed at room temperature and atmospheric pressure and are relatively inexpensive, and also the reaction speed is fast (8). Advanced oxidation such as photochemical oxidation, wet catalytic oxidation, sonochemical oxidation, $\mathrm{O}_{3}$ oxidation, electrochemical oxidation and Fenton oxidation are widely used for direct mineralization of organic contaminants or to improve the degradability of organic contaminants $(9,10)$. Compared to other advanced oxidation processes, Fenton-Based processes (FPs) are the most popular due to some significant advantages such as wide application range, strong anti-interference ability, simple operation, fast degradation and mineralization $(2,11-14)$. The chemical reaction of ferric iron ions and hydrogen peroxide releases hydroperoxy radicals that regenerate catalysts (ferro ions) $(15,16)$. If the reaction starts with $\mathrm{Fe}^{+3}$ instead of $\mathrm{Fe}^{+2}$, it is known as a Fenton-like process (17). FPs consist of two classes of homogeneous and heterogeneous processes; One of the problems in the homogeneous Fenton process is the production of iron sludge (possibly "ferric iron") followed by sludge disposal costs at the end of the process, which is estimated to be approximately 10 to $50 \%$ of the total costs associated with the wastewater treatment process. While the use of solid catalysts in the heterogeneous process of Fenton, an efficient way to reduce sludge has been developed $(15,18-21)$. The chemical reaction of ferric ions and hydrogen peroxide releases hydroperoxy radicals that regenerate catalysts.

Various factors such as temperature, $\mathrm{pH}, \mathrm{H}_{2} \mathrm{O}_{2}$ concentration, iron ion content, contact time, etc. affect the efficiency of FPs processes (22-26). Performance of FPs processes are different; Comparison between Fenton, EF, Sono-ElectroFenton (SEF) and PEF processes for phenol removal showed that the degradation efficiency of the processes is as follows: $\mathrm{PEF}<\mathrm{SEF}<\mathrm{EF}<$ Fenton (27). In the Photo Catalysis / PEF hybrid system 85\% of TOC and 96\% of COD were removed from effluent containing Polyaniline (28).

Testing all the parameters for different Fenton process requires a lot of time and cost, but in such cases, the experiment design method can be used. The Taguchi method is one of the experiment design that compared to factor methods provides advantages such as less number of experiments and therefore less cost and time of testing, the ability to evaluate the interaction effects and conducting experiments in parallel and ultimately predicting the Suitable response.

52 In general, this method reduces the number of experiments required for optimization and increases the accuracy of the 53 results. The most important and effective factor can be determined with this method $(29,30)$ One of the important 54 issues in electrochemical processes is selecting the right electrode (especially anode). The anodes such as BDD ${ }^{5}, \mathrm{Pt}$, and $\mathrm{DSA}^{6}$ due to produce more powerful $\left(\mathrm{OH}^{\circ}\right)$ have shown their high potential in removing various contaminants

\footnotetext{
${ }^{5}$ Boron-doped diamond

${ }^{6}$ Dimensionally stable anodes
} 
57 identical electrodes of $\mathrm{Na}_{2} \mathrm{SO}_{4}$ (42); graphite electrodes (43) and identical BBD electrodes (32) in the Fenton based processes and achieved good results.

59 Khuzestan province in southwestern Iran has large industries such as oil and steel industries. High effluent pollution

60 of oil desalination units and the presence of high slag in the steel industry are among the environmental problems of

61 this region. Hence, the reuse of industrial effluents and steel slag by scientists, engineers and government officials to

62 overcome the region's environmental problems is considered an important issue. Since, in novel research, the use of

63 solid iron catalysts or iron-modified cathodes with it has shown good performance (44), therefore steel slag

64 (containing iron compounds) was used as catalysts and electrodes. The present study aimed to compare different FPs

65 processes in reducing pollution of petroleum industry effluents by using waste materials (steel industry slag). Also,

66 the most effective parameters for reducing COD were identified in each of the processes using the Taguchi method.

\section{2. Materials and methods}

68 This study was designed and implemented to evaluate the efficiency of Fenton, PF, EF and PEF processes in reducing

69 COD from effluents of petroleum desalination unit to reach evacuation standards in Iran, and its excessive reduction

70 is not cost-effective.

71 In addition to, the effect of factors such as $\mathrm{pH}$, contact time, catalyst content, hydrogen peroxide content, radiant

72 intensity and current on the reduction efficiency of COD was investigated. The measured parameters of the effluent

73 of one of the desalination units, by the petroleum-rich areas of the south have been presented Table (1). The catalysts

74 for all four processes of F, EF, PF and PEF were selected from fine particle slag; also copal slag because of its

75 nature was used as the cathode and anode for EF and PEF processes. According the XRF analysis (Table 2), the

76 compounds of iron oxide and calcium oxide have the highest amount. Also, Table (3) shows the wavelengths of the

77 different functional groups; Comparing it with Figure (1), which is related to the functional groups of steel slag, it was

78 found that steel slag contains tensile functional groups - $\mathrm{CH}$ containing nitrate and $\mathrm{C}=\mathrm{O}$ (acid). The experiments were

79 designed using Taguchi orthogonal array and Minitab 18 software. The results of the experiments were analyzed using

80 Microsoft Office Excel and Minitab 18 software using two types of signal analysis to noise and variance.

\section{$81 \quad$ 2.1. Experiment design}

82 The Taguchi method was used in order to reduce the number of experiments and considering the temperature has been 83 one of the important parameters during the processes. Hence, signal-to-noise and ANOVA analysis has been 84 investigated. This method minimizes the number of experiments required using orthogonal arrays. Arrays $L_{9}\left(3^{4}\right)$ 85 and $L_{27}\left(3^{6}\right)$ were used to determine the appropriate conditions based on this statistical model; this means that 4 and 866 effective parameters were selected as arrays, respectively, and examined at three levels, as shown in Tables (4).

87 Achieving Suitable conditions for a specific objective in Taguchi method is based on the signal to noise index S/N. $88 \mathrm{~S} / \mathrm{N}$ is the transformed value of the loss function used to measure the deviation of the performance characteristic from 89 the ideal value. The higher S/N indicate the better performance of the system (45). The calculation method of S/N is 

selected according to the to the intended purpose. Here, according to the goal of achieving the maximum range, S/N

92

\begin{tabular}{|c|c|c|c|c|c|c|c|c|}
\hline parameters & Amounts & the unit & parameters & Amounts & the unit & parameters & Amounts & the unit \\
\hline$S_{4}$ & 410 & $\mathrm{ppm}$ & $P O_{4}$ & 1.3 & $\mathrm{ppm}$ & $\mathrm{pH}$ & 5.33 & - \\
\hline $\mathrm{F}$ & 4.5 & $\mathrm{ppm}$ & $\mathrm{NO}_{3}$ & 1.55 & $\mathrm{ppm}$ & $\mathrm{TDS}$ & 181000 & $\mathrm{ppm}$ \\
\hline $\mathrm{CO}_{3}$ & $<0.1$ & $\mathrm{ppm}$ & $\mathrm{NO}_{2}$ & 0.15 & $\mathrm{ppm}$ & $\mathrm{EC}$ & 362000 & $\mu \mathrm{S} / \mathrm{cm}$ \\
\hline $\mathrm{HCO}_{3}$ & 9 & $\mathrm{ppm}$ & $\mathrm{Cl}$ & 102930 & $\mathrm{ppm}$ & $\mathrm{COD}$ & $>10000$ & $\mathrm{ppm}$ \\
\hline $\mathrm{Bi}$ & $<0.1$ & $\mathrm{ppm}$ & $\mathrm{Ba}$ & $<0.1$ & $\mathrm{ppm}$ & $\mathrm{Ag}$ & $<0.1$ & $\mathrm{ppm}$ \\
\hline $\mathrm{Ca}$ & 60804 & $\mathrm{ppm}$ & $\mathrm{Be}$ & $<0.2$ & $\mathrm{ppm}$ & $\mathrm{Al}$ & $<100$ & $\mathrm{ppm}$ \\
\hline $\mathrm{Co}$ & $<1$ & $\mathrm{ppm}$ & $\mathrm{Ce}$ & $<1$ & $\mathrm{ppm}$ & $\mathrm{Cd}$ & $<0.1$ & $\mathrm{ppm}$ \\
\hline $\mathrm{Mg}$ & 6243 & $\mathrm{ppm}$ & $\mathrm{Fe}$ & 342 & $\mathrm{ppm}$ & $\mathrm{Cr}$ & 4 & $\mathrm{ppm}$ \\
\hline $\mathrm{Li}$ & 41 & $\mathrm{ppm}$ & $\mathrm{Mo}$ & $<0.3$ & $\mathrm{ppm}$ & $\mathrm{Cs}$ & $<0.5$ & $\mathrm{ppm}$ \\
\hline $\mathrm{K}$ & 4993 & $\mathrm{ppm}$ & $\mathrm{Mn}$ & 6 & $\mathrm{ppm}$ & $\mathrm{Cu}$ & $<3$ & $\mathrm{ppm}$ \\
\hline $\mathrm{P}$ & 10 & $\mathrm{ppm}$ & $\mathrm{Zn}$ & 5 & $\mathrm{ppm}$ & $\mathrm{Na}$ & $<10$ & $\mathrm{ppm}$ \\
\hline $\mathrm{Pb}$ & 3 & $\mathrm{ppm}$ & $\mathrm{Ni}$ & 2 & $\mathrm{ppm}$ & $\mathrm{V}$ & 5 & $\mathrm{ppm}$ \\
\hline & & & & & & $\mathrm{S}$ & 972 & $\mathrm{ppm}$ \\
\hline
\end{tabular}

Table 1. Chemical properties of petroleum effluent used
94

95 96

97

98

99

100 
Table 3. Functional groups

\begin{tabular}{|c|c|}
\hline Wavenumber $\left(\mathrm{cm}^{-1}\right)$ & Assignment \\
\hline 3573 & O-H stretch (water) \\
\hline 3319,3208 & O-H stretch (water of hydration) \\
\hline $3100-3000$ & =C-H stretches \\
\hline $3000-2800$ & -C-H stretches \\
\hline 2230 & Nitrile stretch \\
\hline 1647 & C=O stretch (acid) \\
\hline 1566 & C=O stretch (carboxylate) and C=C stretches \\
\hline 1517,1505 & C=C stretches \\
\hline 1425 & C-H deformation and C=C stretches \\
\hline $1258,1167,1142$ & C-O stretches \\
\hline $811,777,734$ & aromatic C-H deformations \\
\hline & \\
\hline
\end{tabular}

102

103 
Table 4. Variables and levels

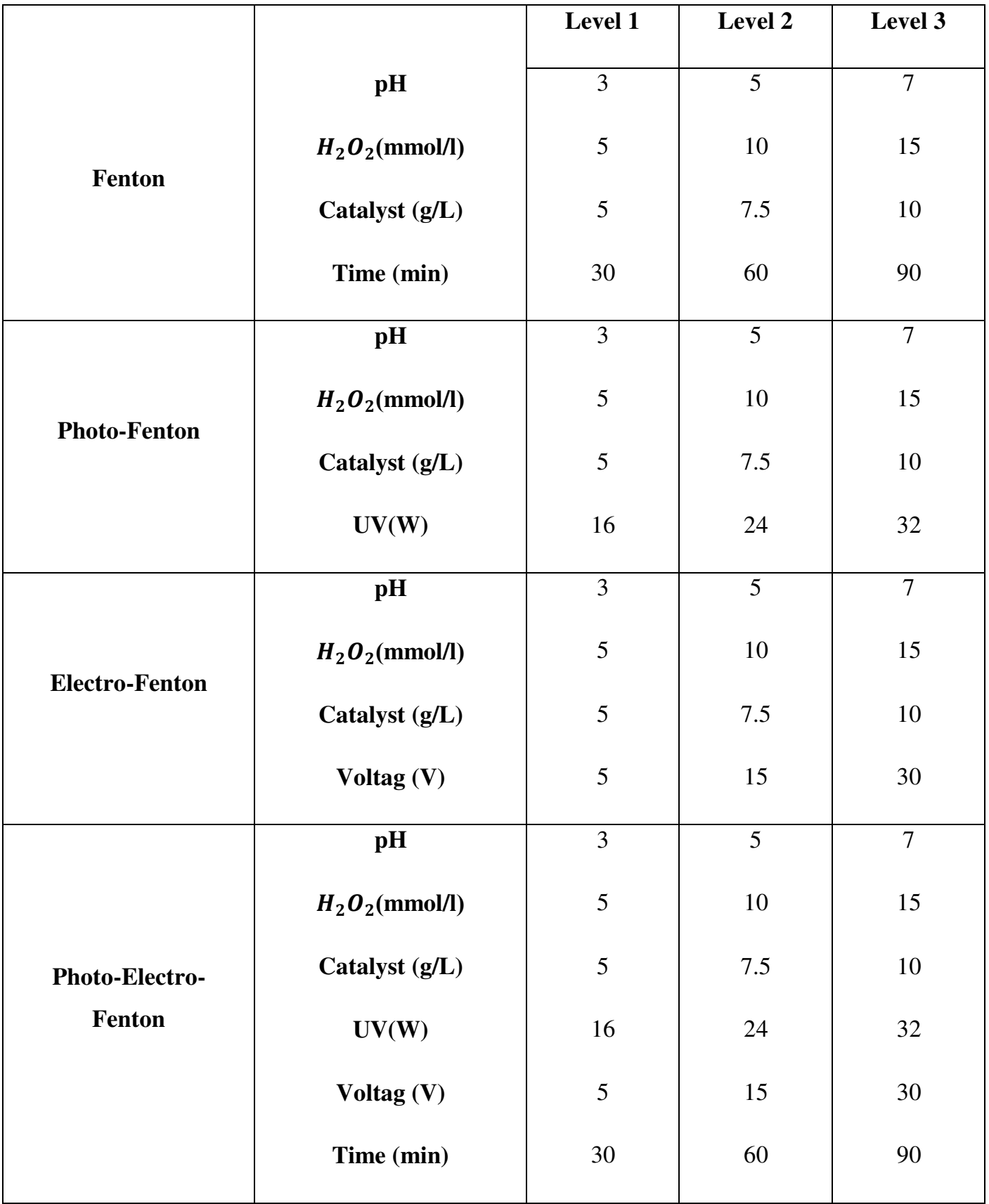

116 Solutions of sulfuric acid (98.08\%), nitric acid (63.01\%), sodium hydroxide (98\%) for $\mathrm{pH}$ adjustment according to 117 Taguchi orthogonal arrays design and $\mathrm{H}_{2} \mathrm{O}_{2}$ concentration (29-31\%) were prepared from Merck Germany for 118 experiments. 
All experiments related to Fenton were performed on a 1250-cc beaker with a diameter of $90 \mathrm{~mm}$ and a height of 150 $\mathrm{mm}$. To perform the PF test, a black box designed from wood was used to prevent the radiation from penetrating into the medium and to have a higher efficiency. In order to produce radiation from $4 \mathrm{UV}-\mathrm{C}$ lamps with a wavelength of 200 to $280 \mathrm{~nm}$ each with a power of $8 \mathrm{~W}$ and a total of $32 \mathrm{~W}$, were installed vertically on all four sides of the box and a glass beaker with a volume of $1250 \mathrm{ml}$ was placed exactly in the middle of the box so that of radiation should be uniformly reflected on the sample from each side. To perform an EF test, a Pyrex beaker with a volume of $1250 \mathrm{ml}$ was used as the reaction medium, and the cathode and anode, both made of Copal slag, were placed in unknown shapes at a distance of $3 \mathrm{~cm}$ from each other. The power supply in this experiment was a variable voltage device of DAZHENG model PS-302 D with variable current characteristics of 0 to $2 \mathrm{~A}$ and variable voltage of 0 to $30 \mathrm{~V}$. The required catalyst content and the required hydrogen peroxide (according to the required level) were added to each sample. In the combined state of PEF, two small holes (with the size of a wire) are made in the upper part of the black box, and the power cords of the cathode and anode are passed through them and connected to the AC power supply (Figure(2)).

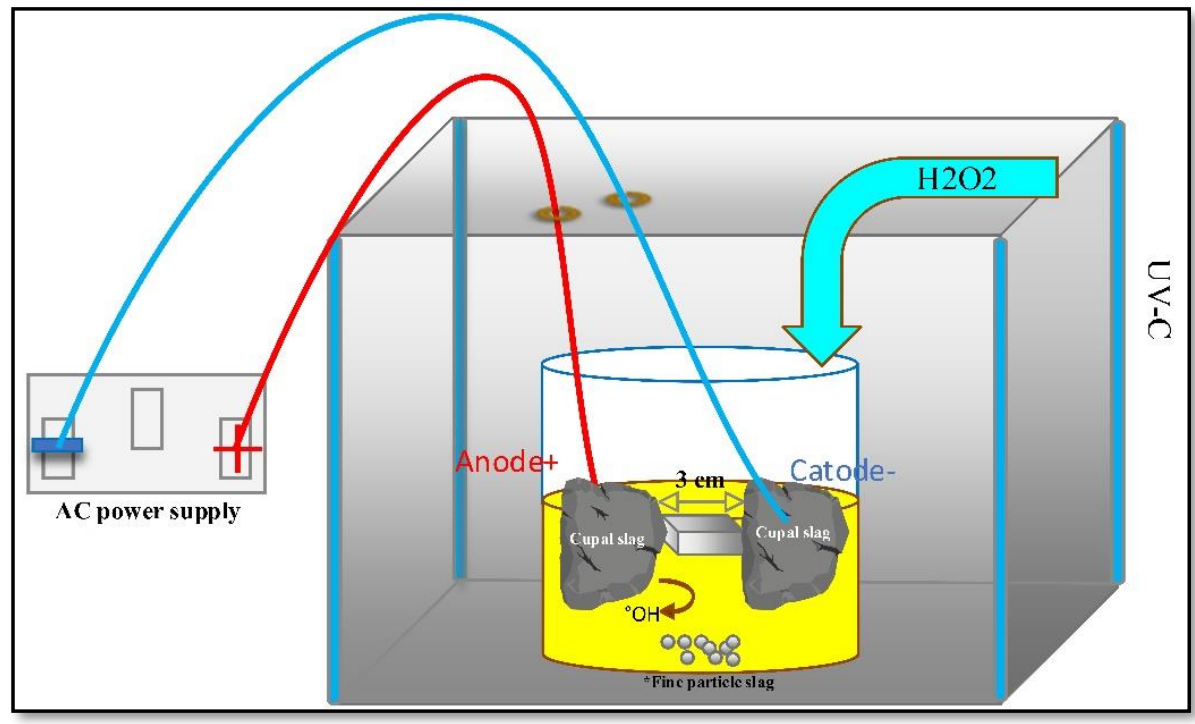

Fig. 2 : Schematic Diagram of The Experimental PEF System

\subsection{Test Method}

For FPs processes, the required amount of slag as catalyst, cathode and anode was washed and then dried in an oven at $105{ }^{\circ} \mathrm{C}$ for 2 hours. Hydrogen peroxide and $0.1 \mathrm{~N}$ sodium hydroxide solutions were prepared. Then the $\mathrm{pH}$ value was adjusted using sulfuric acid and $0.1 \mathrm{~N}$ sodium hydroxide (portable $\mathrm{pH}$ meter model $330 \mathrm{I}$ - WTW Germany). Certain catalyst content (weighed with a Japanese GF300 scale with an accuracy of $0.001 \mathrm{~g}$ ) and hydrogen peroxide were added to the samples and the retention times according to the intended levels were applied using a stopwatch. 
142 After performing experiments related to Fenton process and complementary experiments, the time parameter of 60 143 minutes was considered as the Suitable parameter for PF and EF processes.

144 To perform the PF test, the cathode and anode were both made of slag in unknown shapes placed at the distance of 3 $145 \mathrm{~cm}$. The required catalyst content and required hydrogen peroxide (Table 4) was added to each test sample and, the 146 required retention time was applied.

147 Before and after the experiments, a certain volume of sample was taken and the COD content was measured using a 148 spectrophotometer (Hach 5000) by closed reverse digestion (600 nm wavelength) (47). Then the percentage of COD 149 removal was calculated according to Equation (1).

(1) Removal percentage $=100 \times \frac{C_{0}-C_{1}}{C_{0}}$

Where $C_{0}$ and $C_{1}$ present the initial and final concentrations of COD, respectively.

\subsection{Statistical analysis of data}

After the experiments, signal-to-noise analysis and analysis of variance were performed on the removal percentages

$$
\frac{S}{N}=-10 \log \frac{\sum_{i=1}^{r} \frac{1}{y_{i}^{2}}}{r}
$$

Where $y_{i}$ represents the response value for each experiment and $\mathrm{r}$ denotes the number of repetitions of each 157 experiment.

\section{Results and discussion}

The Taguchi method provided 9 experiments for each of the Fenton, PF and EF methods and 27 experiments for the combined PEF method. The experiments were performed and the results were analyzed using MINTAB 18 software.

\subsection{Fenton}

Table (5) shows the average COD removal rate at different levels of each factor and Figure (3-a) displays the main effects for the signal-to-noise ratio in Fenton experiments. The highest and lowest removal percentages in the 9 experiments were $73.99 \%$ and $26.81 \%$, respectively. Considering the range of slope variation, it can be said that the hydrogen-oxygen parameter has been the most effective factor on the Fenton process. The appropriate levels for each of the factors influencing the process are at the highest point, or the so-called highest signal-to-noise ratio, which, will result in the highest COD removal rate when applied. Therefore, the appropriate conditions to achieve the maximum response value are when $\mathrm{pH}=7, \mathrm{H}_{2} \mathrm{O}_{2}=10 \mathrm{mmol} / \mathrm{l}$, catalyst $=10 \mathrm{gram} / \mathrm{liter}$ and time is $60 \mathrm{~min}$. Experimental factors in terms of maximum impact can be ranked according to the delta value (difference between the highest and lowest 
Table 5. The average response value at different levels of each factor

\begin{tabular}{|c|c|c|c|c|c|c|}
\hline & & Level 1 & Level 2 & Level 3 & Delta & grade \\
\hline \multirow{4}{*}{ Fenton } & pH & 51.75 & 40.72 & 65.63 & 24.91 & 2 \\
\hline & $\mathrm{H}_{2} \mathrm{O}_{2}(\mathrm{mmol} / \mathrm{l})$ & 37.21 & 69.5 & 51.39 & 32.28 & 1 \\
\hline & Catalyst (g/L) & 44.9 & 48.48 & 64.73 & 19.83 & 3 \\
\hline & Time (min) & 51.05 & 54.99 & 52.07 & 3.94 & 4 \\
\hline \multirow{4}{*}{ Photo-Fenton } & pH & 72.35 & 62.54 & 29.45 & 42.9 & 1 \\
\hline & $\mathrm{H}_{2} \mathrm{O}_{2}(\mathrm{mmol} / \mathrm{l})$ & 65.92 & 52.66 & 45.76 & 20.15 & 3 \\
\hline & Catalyst (g/L) & 46.04 & 55.48 & 62.82 & 16.78 & 4 \\
\hline & $\mathbf{U V}(\mathbf{W})$ & 45.95 & 51.6 & 66.8 & 20.85 & 2 \\
\hline \multirow{4}{*}{ Electro-Fenton } & pH & 56.51 & 63.55 & 66.19 & 9.68 & 4 \\
\hline & $\mathrm{H}_{2} \mathrm{O}_{2}(\mathrm{mmol} / \mathrm{l})$ & 86.13 & 35.03 & 65.09 & 51.11 & 1 \\
\hline & Catalyst (g/L) & 69.81 & 60.29 & 56.15 & 13.66 & 3 \\
\hline & Voltag (V) & 57.34 & 71.2 & 57.71 & 13.85 & 2 \\
\hline \multirow{6}{*}{$\begin{array}{c}\text { Photo-Electro- } \\
\text { Fenton }\end{array}$} & pH & 73.04 & 74.38 & 71.15 & 3.23 & 6 \\
\hline & $\mathrm{H}_{2} \mathrm{O}_{2}(\mathrm{mmol} / \mathrm{l})$ & 65.09 & 82.17 & 71.31 & 17.08 & 3 \\
\hline & Catalyst (g/L) & 79.63 & 63.84 & 75.09 & 15.79 & 4 \\
\hline & $\mathbf{U V}(\mathbf{W})$ & 64.06 & 79.38 & 75.12 & 15.32 & 5 \\
\hline & Voltag (V) & 61.81 & 80.19 & 76.57 & 18.39 & 2 \\
\hline & Time (min) & 54.3 & 84.68 & 79.6 & 30.38 & 1 \\
\hline
\end{tabular}

174 Basically, the Suitable contact time is a very important parameter in chemical reactions and if it exceeds the Suitable

175 limit, the process will no longer be economic (49). The optical contact time of 60 min obtained in some other research

176 (50).The highest COD removal percentage occurs at $\mathrm{pH} 7$ for the Fenton process. However, some previous studies

177 have shown that the Fenton process in the acidic state shows better performance (2).The contaminant adsorption rate

178 on the catalyst surface increases with increasing the number of catalyst particles and the available surface area, which

179 leads to the production of more hydroxyl radicals (51). By increasing the concentration of hydrogen peroxide from 5

180 to $10 \mathrm{mmol} / \mathrm{L}$, the COD removal percentage increases and then decreases with increasing $\mathrm{H}_{2} \mathrm{O}_{2}$ to $15 \mathrm{mmol} / \mathrm{L}$. Excess

181 concentration of $\mathrm{H}_{2} \mathrm{O}_{2}$ can act as a hydroxyl radical scavenger. It acts instead of a hydroxyl radical, $\mathrm{HO}_{2} \bullet$, which has

182 less oxidizing ability and longer life compared to $\mathrm{OH} \bullet(52)$. 

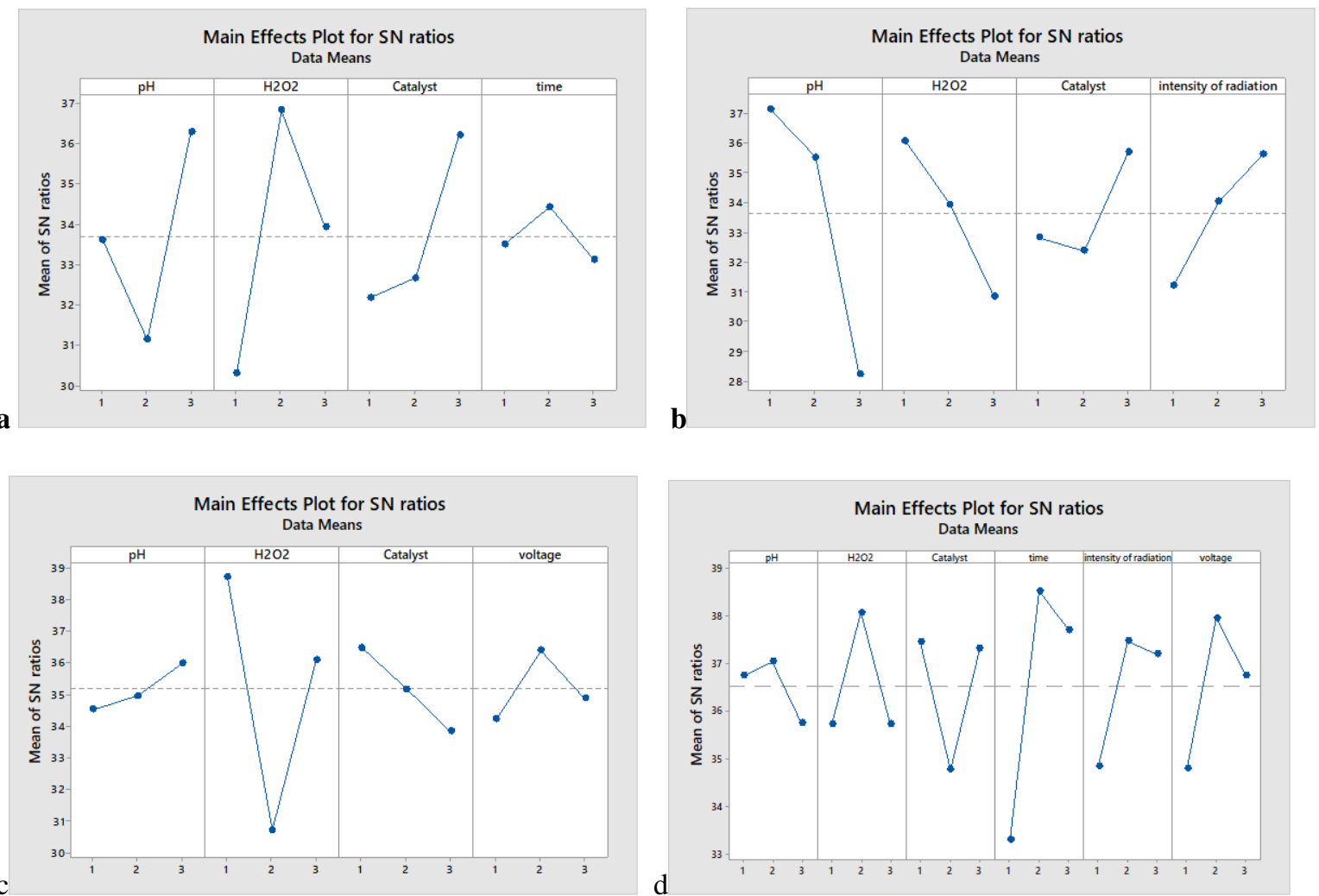

Fig. 3: Diagram of the main effects for the signal-to-noise ratio related to the COD removal percentage.

a) Fenton process, b) PF process c) EF process, d) PEF process

\subsection{Photo-Fenton}

The maximum and minimum chemical oxygen demand in 9 experiments were 86.39 and $12.30 \%$, respectively. The average COD removal rate at each level and for each factor has been shown in Table (5) and the main effects for the signal-to-noise ratio have been shown in Figure (3-b).

According to Figure (3-b), the most effective factor in the PF process was pH. Delta values in Table (5) also show that after $\mathrm{pH}$, the most important factors are radiant intensity, hydrogen peroxide and catalyst, respectively. The appropriate levels for each of the factors influencing the process are at the highest point or so-called maximum signalto-noise ratio. Therefore, the best conditions for $\mathrm{PF}$ test are $\mathrm{pH}=3, \mathrm{H}_{2} \mathrm{O}_{2}=5 \mathrm{mmol} / \mathrm{l}$, catalyst $=10 \mathrm{gram} / \mathrm{liter}$ and radiant intensity is $32 \mathrm{~W}$.

As the radiant intensity increases, the potential for hydroxyl radical generation increases, resulting in higher COD removal rate. According to the diagram, it can be said that the Suitable radiant intensity is equal to $32 \mathrm{~W}$. This finding is consistent with a study by Chinese researchers (using a $30 \mathrm{~W}$ lamp) for the PF process. (53). The most effective factor in this experiment was $\mathrm{pH}$, which obtained the best conditions at an acidic value of $\mathrm{pH}=3$ unlike Fenton. The effect of this parameter on the PF process has been expressed differently in previous research. Some have preferred acidic $\mathrm{pH}$ (54) and some alkaline $\mathrm{pH}$ (52). Therefore, after $\mathrm{pH}$, factor radiant intensity, hydrogen peroxide and catalyst 
factors had the greatest effect on COD removal percentage, respectively (Figure (3-b) and Table 5). The hydrogen peroxide content at the lowest experimental value has given the best result which is consistent with other research (54). The amount of $\mathrm{HO}_{2} \bullet$ (which has less oxidizing ability) increase at high level of $\mathrm{H}_{2} \mathrm{O}_{2}$ (52). As with the Fenton process, the highest COD removal rate is associated with the highest catalyst content.

\subsection{Electro-Fenton}

9 experiments were performed for the EF process, the highest and lowest COD removal rates were $93.42 \%$ and $25.82 \%$, respectively. Table (5) and Figure (3-c) show the average COD removal rate at each level for each factor and the main effects for the S/N ratio. Given the signal-to-noise for each level of factors (Figure 3-c), the appropriate conditions for achieving the maximum response value are when the $\mathrm{pH}$ factors are at the third level $(\mathrm{pH}=7)$, the voltage is at the second level $(15 \mathrm{~V})$, and the hydrogen peroxide and the catalyst contents are in the first level (5 $\mathrm{mmol} / \mathrm{l}$ and $5 \mathrm{gram} / \mathrm{liter}$, respectively).

The most effective factor is hydrogen peroxide and after that catalyst, voltage and $\mathrm{pH}$, respectively, were effective on the EF process in the COD removal percentage (Figure 3-c). As with Fenton and PF conditions, the lowest hydrogen peroxide content has had the best response. But in the case of the catalyst in this process, these two reversal processes of Fenton and PF, lower catalyst content has provided more appropriate results. The $\mathrm{pH}$, similar to the Fenton process, has performed better under neutral conditions.

\subsection{Photo-Electro-Fenton}

221 According to Taguchi design for this process, 27 experiments were performed. The highest COD removal rate was $22298.78 \%$ and the lowest was $14.59 \%$. Table (5) shows the average COD removal rate at different levels of each factor 223 and Figure (3-d) shows the main effects for the signal-to-noise ratio in PEF experiments.

224 According to the slope of variations in Figure (3-d), it can be said that the most effective factors are time, voltage, catalyst, radiant intensity, hydrogen peroxide and $\mathrm{pH}$, respectively. In this experiment, the highest COD removal rate will occur when the Suitable conditions for achieving the maximum response value include $\mathrm{pH}=5, \mathrm{H}_{2} \mathrm{O}_{2}=10 \mathrm{mmol} / \mathrm{l}$, catalyst $=5$ gram/liter, $24 \mathrm{~W}$ radiant intensity, $15 \mathrm{~V}$ and 60 minutes time.

Statistical analysis was performed to confirm the results of Taguchi method. Given the number of experiments performed on different processes, this study was feasible for the PEF process. Analysis of linear model of variance was performed for signal-to-noise ratio values and mean COD (Table 6). The results of multivariate analysis of variance showed that the time factor is significant at the level of one percent and the other parameters do not have a significant effect on the output variable. The study of the main effects of $\mathrm{S} / \mathrm{N}$ ratio also showed a large effect of the time parameter. The R2 value of the linear model was $61.65 \%$ and the $\mathrm{S}$ value was 10.7354 . The parameter $\mathrm{S}$ is used instead of $R^{2}$ to compare the suitability of models without any constant. The value of $\mathrm{S}$ is measured in response variable units and indicates how much the data values fall from the corresponding values. The lower the $S$ value, the better the model describes the response. However, a low value of $\mathrm{S}$ or a high value of the coefficient of determination 
do not in themselves indicate that the model conforms to the assumptions of the model; The residual diagrams should be examined to validate the hypotheses (Figure 4). According to Figure (4), the residual values have been placed around the zero line, indicating the accuracy of the model. As observed in the NPP diagram, the points are almost on a straight line, indicating that the data is approximately normal. The residual versus order diagram is plotted for the independence of the observations. Given that the data are located around the horizontal axis, it can be said that our observations are completely independent and there is no correlation between them. According to the versus Fits diagram, it can be said that the assumption that the variances are constant is accepted. The shape of the histogram has a positive or straight skew. This means that the data have dissymmetry relative to the mean, and the larger data lead to the lower frequency.

Table 6. Analysis of variance for signal to noise ratio and COD values

\begin{tabular}{|c|c|c|c|c|c|c|}
\hline \multirow{2}{*}{ Source } & \multicolumn{3}{|c|}{ S/N } & \multicolumn{3}{c|}{ COD } \\
\cline { 2 - 7 } & DF & Seq SS & P & DF & Seq SS & P \\
\hline pH & 2 & 8.332 & 0.682 & 2 & 47.3 & 0.931 \\
\hline H2O2 & 2 & 33.093 & 0.245 & 2 & 1344.7 & 0.167 \\
\hline Catalyst & 2 & 40.981 & 0.182 & 2 & 1189.1 & 0.201 \\
\hline time & 2 & 142.693 & 0.009 & 2 & 4765.7 & 0.007 \\
\hline UV & 2 & 37.218 & 0.209 & 2 & 1125.4 & 0.217 \\
\hline Voltage & 2 & 45.613 & 0.153 & 2 & 1707.2 & 0.111 \\
\hline Residual error & 14 & 148.541 & & 14 & 4616.3 & \\
\hline Total & 26 & 456.471 & & 26 & 14795.9 & \\
\hline
\end{tabular}

Then, Tukey test was used to find the factor or factors that have a significant difference with other factors.

Table (7) shows a Tukey pairwise comparison at the 95\% confidence level. The results of Tukey test also showed that the factor of time has a significant difference with other factors for COD removal in the PEF process. 


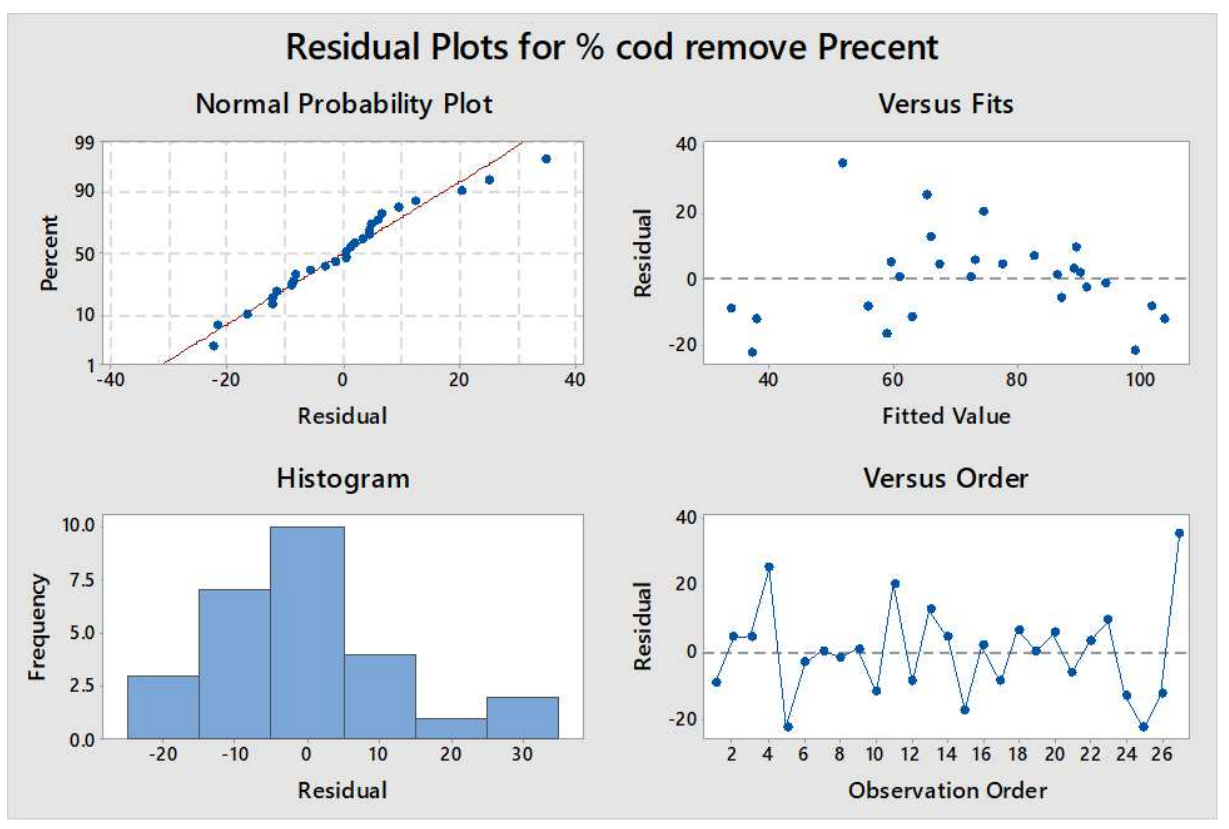

Fig. 4: Residual diagrams for COD removal percentage

Table 7. Tukey pairwise comparison at $95 \%$ confidence level (COD removal in PEF process)

\begin{tabular}{|c|c|c|c|c|}
\hline Parameter & level & N & Avarage & Group \\
\hline \multirow{3}{*}{ pH } & 2 & 9 & 74.3771 & $\mathrm{~A}$ \\
& 1 & 9 & 73.0413 & $\mathrm{~A}$ \\
$\mathbf{3}$ & 3 & 9 & 71.1509 & $\mathrm{~A}$ \\
\hline \multirow{3}{*}{ Catalyst } & 2 & 9 & 82.17 & $\mathrm{~A}$ \\
& 3 & 9 & 71.3064 & $\mathrm{~A}$ \\
& 1 & 9 & 65.0929 & $\mathrm{~A}$ \\
\hline \multirow{3}{*}{ Time } & 3 & 9 & 79.6327 & $\mathrm{~A}$ \\
& 2 & 9 & 75.092 & $\mathrm{~A}$ \\
& 3 & 9 & 63.8446 & $\mathrm{~A}$ \\
\hline \multirow{3}{*}{ UV } & 1 & 9 & 84.6752 & $\mathrm{~A}$ \\
& 2 & 9 & 59.5962 & $\mathrm{~A}$ \\
& 3 & 9 & 54.2979 & $\mathrm{~B}$ \\
\hline \multirow{3}{*}{ Voltage } & 1 & 9 & 79.3821 & $\mathrm{~A}$ \\
& 2 & 9 & 64.0633 & $\mathrm{~A}$ \\
& 3 & 9 & 80.194 & $\mathrm{~A}$ \\
\hline
\end{tabular}

* Averages with different letters are significantly different from the others 
The results of process PEF showed that with increasing this parameter, COD removal efficiency was increased first and then reduced. $\mathrm{H}$ ions played the scavenging role of hydroxyl radicals due to $\mathrm{H}$ high concentration at low $\mathrm{pH}$ and reduced the COD removal efficiency $(2,55)$. Also, the solubility of ferrous ions might be decreased with increasing the $\mathrm{pH}$ of the solution, which adversely affected the production of hydroxyl radicals. Since at the high $\mathrm{pH}$, the ferric-

272 hydroxo complexes is produced as a consequence of ferric ions and the hydroxide ions reaction, the production of

273 hydroxyl radicals would be slower (Equations (3) and (4)); finally, this complex had the tendency to polymerize at the pH 4 to 7 (Equations (5), (6) and (7)). Therefore, the range outside the acidic pH resulted in fostering iron ion-driven coagulation which could decrease the removal efficiency of the organic materials $(56,57)$. Hence, the maximum COD removal at $\mathrm{pH} 5$ was due to the reaction with hydroxyl radicals.

(4) $\left[\mathrm{Fe}\left(\mathrm{H}_{2} \mathrm{O}\right)_{5} \mathrm{OH}\right]^{2+}+\mathrm{H}_{2} \mathrm{O} \rightarrow\left[\mathrm{Fe}\left(\mathrm{H}_{2} \mathrm{O}\right)_{4}(\mathrm{OH})_{2}\right]^{+}+\mathrm{H}_{3} \mathrm{O}^{+}$

(5) $2\left[\mathrm{Fe}\left(\mathrm{H}_{2} \mathrm{O}\right)_{5} \mathrm{OH}\right]^{2+} \rightarrow\left[\mathrm{Fe}_{2}\left(\mathrm{H}_{2} \mathrm{O}\right)_{8}(\mathrm{OH})_{2}\right]^{4+}+2 \mathrm{H}_{2} \mathrm{O}$

(6) $\left[\mathrm{Fe}_{2}\left(\mathrm{H}_{2} \mathrm{O}\right)_{8}(\mathrm{OH})_{2}\right]^{4+}+\mathrm{H}_{2} \mathrm{O} \rightarrow\left[\mathrm{Fe}_{2}\left(\mathrm{H}_{2} \mathrm{O}\right)_{7}(\mathrm{OH})_{3}\right]^{3+}+\mathrm{H}_{3} \mathrm{O}^{+}$

$$
\text { (7) }\left[\mathrm{Fe}_{2}\left(\mathrm{H}_{2} \mathrm{O}\right)_{7}(\mathrm{OH})_{3}\right]^{3+}+\left[\mathrm{Fe}\left(\mathrm{H}_{2} \mathrm{O}\right)_{5} \mathrm{OH}\right]^{2+} \rightarrow\left[\mathrm{Fe}_{3}\left(\mathrm{H}_{2} \mathrm{O}\right)_{5}(\mathrm{OH})_{4}\right]^{5+}+2 \mathrm{H}_{2} \mathrm{O}
$$

Considering previous researches, little information is available on the performance of the heterogeneous PEF process. On the other hand, in these studies, most experiments have been performed on acidic $\mathrm{pH}$ (where catalysts can be partially dissolved) $(28,31,58-62)$. Thus, the efficiency of this process in neutral $\mathrm{pH}$ was also investigated. Experiments demonstrated that Fenton and EF processes performed best in neutral conditions and PF and EPF processes in acidic conditions. In PEF process, the rate of COD removal (due to reduced hydroxyl radical production) decreases near neutral. However, a decrease in system performance is observed at very low pH due to dissolution.

288 This matter has been confirmed in previous research $(63,64)$.

\subsubsection{Effect of voltage}

In the hybrid mode of the PEF process, the voltage level of $15 \mathrm{~V}$ is Suitable which is also economical in terms of energy consumption. Therefore, it can be said that in the PEF process, compared to the EF process, the COD removal efficiency has increased due to the use of radiation by applying a suitable voltage.

\subsubsection{Effect of catalyst}

294 Given that the compound $\mathrm{Fe}_{2} \mathrm{O}_{3}$ forms the major part of slag and has been recognized in previous research as the 295 most effective compound in removing pollution; Therefore, it can play an important role in removing COD contaminants. In addition, the main role of the catalyst is played by slag. The composition $\mathrm{Fe}_{2} \mathrm{O}_{3}$ in steel slag can 
release ferric ions in an acidic solution (while the $\mathrm{pH}$ of the effluent sample is also in the acidic range). Therefore, steel slag containing ferric ions can be used as An inexpensive catalyst in FPs $(55,65,66)$. The experiments showed that the Suitable amount of catalyst in this process is equal to $5 \mathrm{gram} / \mathrm{liter}$. The COD removal decreased for the catalyst amount of $7.5 \mathrm{gram} / \mathrm{liter}$, and it increased again for the amount of $10 \mathrm{gram} / \mathrm{liter}$. This final result being not consistent with the published data by Byrappa et al. (50). Because of the amount of contaminants absorbed on the catalyst surface decreased with the increasing number of catalyst particles. The reason was that the surplus ferrous ions or other compounds of the steel slag could act as scavengers of the hydroxyl radicals in the solution $(2,67,68)$. It can be said that in general, when the amount of catalyst exceeds the Suitable value, due to the turbidity of the environment, UV rays do not effectively reach the surface of the catalyst, and thus the removal efficiency decreases. The conditions of our study are consistent with Bayat et al. (69) in terms of process and acidic environment.

Considering that catalyst values less than $5 \mathrm{~g} / 1$ showed low efficiency in contamination removal during FPs processes. Moreover, The addition of certain amounts of slag catalysts in these processes increased the removal efficiency of the contaminant, thus it can be said that the slag catalyst certainly played an important role in removing COD contamination and can not be ignored.

\subsubsection{Effect of $\mathrm{H}_{2} \mathrm{O}_{2}$}

312 Given that the processes under study are heterogeneous Fenton-like, then $\mathrm{H} 2 \mathrm{O} 2$, as the dominant source of $\mathrm{HO}$. under 313 catalysis, plays a critical role in the treatment of organic effluents (2).

314 According to Figure (3-b), the rate of $10 \mathrm{mmol} / \mathrm{l}$ is Suitable for hydrogen peroxide which is consistent with the research by Felebuegu and Ezenwa (70). They were able to perform wastewater treatment operations during the Fenton-like oxidation process with this amount of hydrogen peroxide and other Suitable conditions. Since the concentration of $\mathrm{HO}_{2} \bullet$ is higher than $\mathrm{OH} \bullet$ in solution, the ability of any reactions of $\mathrm{HO}_{2} \bullet$ is prevalent. It should be noted $\mathrm{HO}_{2} \bullet$ has lower oxidizing ability and a longer lifetime than $\mathrm{OH} \bullet(51)$.

319 On the other hand, The surplus molecules of hydrogen peroxide might consume hydroxyl radicals, by formation of 320 hydroperoxy radicals (HOO•) which have less reactivity in comparison to hydroxyl radicals. Therefore, the amounts 321 of hydroxyl radicals were reduced and, subsequently, the COD removal efficiency was decreased $(2,20,68)$. Therefore, 322 it is necessary to find the suitable dose Which also depends on various parameters such as temperature, $\mathrm{pH}, \mathrm{COD}$ and 323 total suspended solids of pollutants (71).

\subsubsection{Effect of radiation intensity}

325 Obviously, with increasing radiation intensity, the potential for hydroxyl radical production increases, and thus it 326 causes for increasing the removal efficiency of COD. However, by increasing the radiation from $24 \mathrm{~W}$ to $32 \mathrm{~W}$, due 327 to the high concentration of organic matter, contaminants settle on the catalytic surface and prevent light from reaching 328 the catalyst, ultimately reducing the photocatalytic removal (72). As a result, according to Figure (3-d), it can be said 329 that the Suitable radiation intensity is equal to $24 \mathrm{~W}$, which is consistent with the research of Xing and Sun (52). 
The time factor was not the only influential factor during the processes but it has played a role in eliminating pollution as an important parameter. The COD removal rate increases with increasing contact time. This increased time cause for more photon absorption by the catalyst surface and stimulate the photocatalyst, resulting in more free radical generation of $\mathrm{OH} \bullet$ and higher removal efficiency. As shown in Figure (3-d), the S/N value increases significantly with increasing time to level $2(60 \mathrm{~min})$ and then decreases.

The Suitable contact time in the PEF process for COD removal is 60 minutes. The contact time is a very important parameter in chemical reactions, and if it exceeds the Suitable limit, it will not be an economic process (48). However, it should be noted that with increasing time, the pores of the cathode surface fill with contaminate, which reduces the production of $\mathrm{H}_{2} \mathrm{O}_{2}$ and ultimately reduces the removal efficiency.Babuponnusami and Muthukumar (27), compared different Fenton processes, and found that the amount of pollutant degradation in the PEF process is higher which is consistent with our study.

\subsection{Comparison of the efficiency of different processes for COD removal}

343 In order to evaluate the efficiency of PEF process, the role of Fenton, PF, EF processes on the COD removal was

344 investigated under the conditions of the highest removal percentage obtained. The effect of different processes on 345 COD removal efficiency has been shown in Figure (5). According to Figure (5), it can be seen that PEF, EF, PF and 346 Fenton, respectively, have high efficiency of removing COD from the desalination unit effluent samples. On average, they have between 70 and 100 percent COD removal capability. It seems that dissolved iron in the studied effluent has helped to increase the production of $\mathrm{H}_{2} \mathrm{O}_{2}$ (especially in electrochemical processes) $(73,74)$.

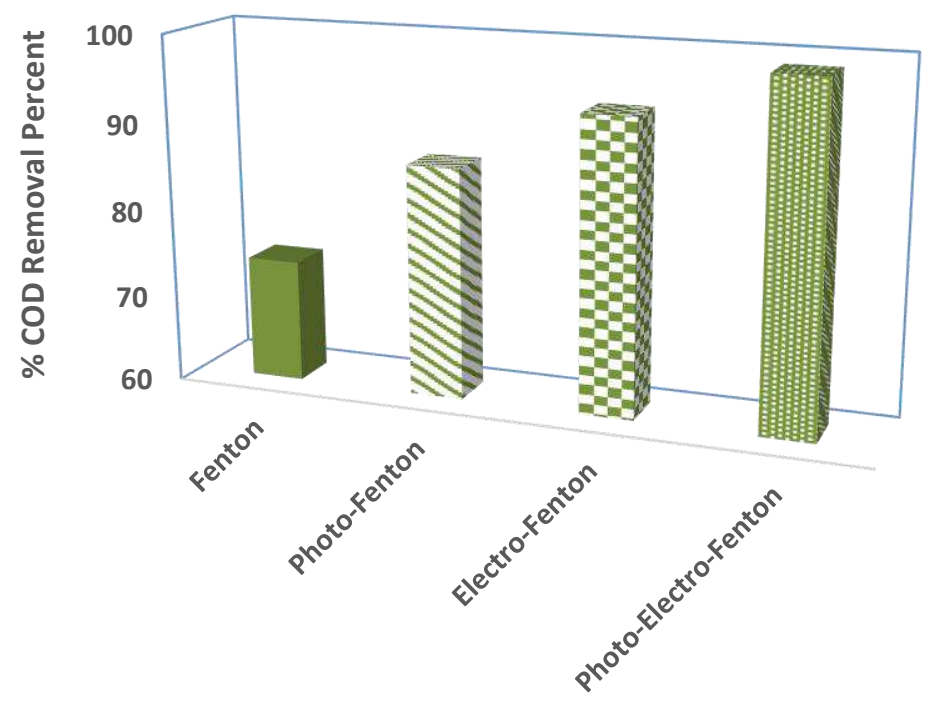




\section{Conclusion}

353 Among the numerous advanced oxidation processes to reduce the chemical oxygen demand of petroleum effluents,

354 FPs methods are prominent. The chemical oxygen demand (COD) in the petroleum contaminated effluent during 355 Fenton, PF, EF and PEF processes under the conditions of maximum removal is 74\%, 86.39\%, 93.42\% and 98.781\%, 356 respectively, which shows that the combined PEF process with the highest rate of COD removal has a greater ability 357 to mineralize the contaminated oil effluent; after that, EF, PF and Fenton processes have a good ability to reduce 358 organic contaminants, respectively.

359 Considering the removal percentages obtained during these processes, it can be said that the slag fine particle catalyst 360 of Khuzestan Steel Industries can be a suitable alternative to iron ions in FPs processes as a catalyst. Also, copal slag 361 of steel industries of Khuzestan province, with suitable electrical resistance and current establishment, can be used as 362 a cathode and anode in FPs electrochemical process. Slag catalyst as a waste of Khuzestan steel industry has a very 363 good potential for the treatment of petroleum industry effluents with very high organic pollution and resistant to 364 biodegradation.

365 Although this study revealed the high potential of steel slag in the Fenton process for COD removal of the industrial 366 effluents, more research is needed to test the process for specific pollutants, particularly types of residual 367 hydrocarbons, Polycyclic aromatic hydrocarbons.

368 The results show that although FPs processes can be used to reduce chemical oxygen demand pollution from petroleum 369 industry desalination effluents; but the combined PEF process has a higher potential than other processes in removing 370 chemical oxygen demand contamination from the effluent. The implementation of this system for the treatment of 371 industrial effluents such as oil is recommended due to its high efficiency in reducing pollution, cost-effectiveness in 372 industry, simplicity of work and ultimately less toxicity.

\section{Acknowledgements}

375 We are grateful to the Research Council of Shahid Chamran University of Ahvaz for financial support (GN:

376 SCU.WI98.25891)

378 Abbreviation signs

379 Gram per liter $=\mathrm{g} / \mathrm{l}$

$380 \quad$ Ampere $=\mathrm{A}$

$381 \quad$ Watt $=\mathrm{W}$

$382 \quad$ Volt $=\mathrm{V}$

383 Millimol per liter $=\mathrm{mmol} / \mathrm{l}$ 
Minutes $=\min$

\section{Declarations}

-Ethics approval and consent to participate: 'Not applicable'

-Consent for publication: 'Not applicable'

-Availability of data and materials: The datasets used and analysed during the current study are available from the corresponding author on reasonable request.

391 -Competing interests: The authors declare that they have no competing interests.

392 -Funding: This research has been financially supported by the Research Council of Shahid Chamran University of 393 Ahvaz.

394 -Authors' contributions: All authors conceived and designed the study. F.E carried out the experiments. Both F.E and P.T analysed the data, wrote the manuscript, and discussed the results. All authors contributed to manuscript revision and approve it.

397 Acknowledgements: We are grateful to the Research Council of Shahid Chamran University of Ahvaz for financial 398 support (GN: SCU.WI98.25891)

\section{Reference}

400 1. Padmanabhan PVA, Sreekumar KP, Thiyagarajan TK, Satpute RU, Bhanumurthy K, Sengupta P, et al. 401 Nano-crystalline titanium dioxide formed by reactive plasma synthesis. Vacuum. 2006;80(11-12):1252-5.

402 2. Wang N, Zheng T, Zhang G, Wang P. A review on Fenton-like processes for organic wastewater treatment.

404 3. Glaze WH. Drinking-water treatment with ozone. Environ Sci Technol. 1987;21(3):224-30.

405 4. Glaze WH, Kang J-W, Chapin DH. The chemistry of water treatment processes involving ozone, hydrogen peroxide and ultraviolet radiation. 1987;

5. Deng Y, Zhao R. Advanced oxidation processes (AOPs) in wastewater treatment. Curr Pollut Reports. 2015;1(3):167-76.

6. Cho M, Chung H, Choi W, Yoon J. Different inactivation behaviors of MS-2 phage and Escherichia coli in TiO2 photocatalytic disinfection. Appl Environ Microbiol. 2005;71(1):270-5.

7. Ikai H, Nakamura K, Shirato M, Kanno T, Iwasawa A, Sasaki K, et al. Photolysis of hydrogen peroxide, an effective disinfection system via hydroxyl radical formation. Antimicrob Agents Chemother. 2010;54(12):5086-91.

8. Gaya UI, Abdullah AH. Heterogeneous photocatalytic degradation of organic contaminants over titanium dioxide: a review of fundamentals, progress and problems. J Photochem Photobiol C Photochem Rev. 2008;9(1):1-12.

9. Bokare AD, Choi W. Review of iron-free Fenton-like systems for activating $\mathrm{H} 2 \mathrm{O} 2$ in advanced oxidation processes. J Hazard Mater. 2014;275:121-35. 
10. Sharma A, Ahmad J, Flora SJS. Application of advanced oxidation processes and toxicity assessment of transformation products. Environ Res. 2018;167:223-33.

11. Chen L, Ma J, Li X, Zhang J, Fang J, Guan Y, et al. Strong enhancement on Fenton oxidation by addition of hydroxylamine to accelerate the ferric and ferrous iron cycles. Environ Sci Technol. 2011;45(9):3925-30.

12. Miklos DB, Remy C, Jekel M, Linden KG, Drewes JE, Hübner U. Evaluation of advanced oxidation processes for water and wastewater treatment-A critical review. Water Res. 2018;139:118-31.

13. Huang D, Hu C, Zeng G, Cheng M, Xu P, Gong X, et al. Combination of Fenton processes and biotreatment for wastewater treatment and soil remediation. Sci Total Environ. 2017;574:1599-610.

14. Barreto-Rodrigues M, Silva FT, Paiva TCB. Optimization of Brazilian TNT industry wastewater treatment using combined zero-valent iron and fenton processes. J Hazard Mater. 2009;168(2-3):1065-9.

15. Neyens E, Baeyens J. A review of classic Fenton's peroxidation as an advanced oxidation technique. J Hazard Mater. 2003;98(1-3):33-50.

16. Duesterberg CK, Cooper WJ, Waite TD. Fenton-mediated oxidation in the presence and absence of oxygen. Environ Sci Technol. 2005;39(13):5052-8.

17. Fu F, Wang Q, Tang B. Fenton and Fenton-like reaction followed by hydroxide precipitation in the removal of Ni (II) from NiEDTA wastewater: a comparative study. Chem Eng J. 2009;155(3):769-74.

18. Munoz M, De Pedro ZM, Casas JA, Rodriguez JJ. Preparation of magnetite-based catalysts and their application in heterogeneous Fenton oxidation-a review. Appl Catal B Environ. 2015;176:249-65.

19. Pliego G, Zazo JA, Blasco S, Casas JA, Rodriguez JJ. Treatment of highly polluted hazardous industrial wastewaters by combined coagulation-adsorption and high-temperature Fenton oxidation. Ind Eng Chem Res. 2012;51(7):2888-96.

20. Zheng J, Gao Z, He H, Yang S, Sun C. Efficient degradation of Acid Orange 7 in aqueous solution by iron ore tailing Fenton-like process. Chemosphere. 2016;150:40-8.

21. Gągol M, Przyjazny A, Boczkaj G. Wastewater treatment by means of advanced oxidation processes based on cavitation-a review. Chem Eng J. 2018;338:599-627.

22. Stepnowski P, Siedlecka EM, Behrend P, Jastorff B. Enhanced photo-degradation of contaminants in petroleum refinery wastewater. Water Res. 2002;36(9):2167-72.

23. Meriç S, Kaptan D, Ölmez T. Color and COD removal from wastewater containing Reactive Black 5 using Fenton's oxidation process. Chemosphere. 2004;54(3):435-41.

24. Mousavi SA, Mahvi AH, Mesdaghinia A, Nasseri S, Honari HR. Fenton oxidation efficiency in removal of detergents from water. J Water Wastewater. 2010;72:16-23.

25. Jaafarzadeh N, Ghanbari F, Moradi M. Photo-electro-oxidation assisted peroxymonosulfate for decolorization of acid brown 14 from aqueous solution. Korean J Chem Eng. 2015;32(3):458-64.

26. Lopez-Saavedra N, Muñoz-Delgado LF, Lara-Ramos JA, Machuca-Martinez F. Experimental data on the degradation of caffeine by photo-electro-fenton using BDD electrodes at pilot plant. Data Br. 2018;21:170915.

27. Babuponnusami A, Muthukumar K. Advanced oxidation of phenol: a comparison between Fenton, electroFenton, sono-electro-Fenton and photo-electro-Fenton processes. Chem Eng J. 2012;183:1-9.

28. Ou B, Wang J, Wu Y, Zhao S, Wang Z. Treatment of polyaniline wastewater by coupling of photoelectroFenton and heterogeneous photocatalysis with black TiO2 nanotubes. ACS Omega. 2019;4(6):9664-72.

29. Yonar T, Kurt A. Treatability studies of hospital wastewaters with AOPs by Taguchi's experimental design. Glob Nest J. 2017;19:505-10. 
30. Suraj P, Kumar V, Thakur C, Ghosh P. Taguchi optimization of COD removal by heterogeneous Fenton process using copper ferro spinel catalyst in a fixed bed reactor-RTD, kinetic and thermodynamic study. $\mathrm{J}$ Environ Chem Eng. 2019;7(1):102859.

31. Ye Z, Steter JR, Centellas F, Cabot PL, Brillas E, Sirés I. Photoelectro-Fenton as post-treatment for electrocoagulated benzophenone-3-loaded synthetic and urban wastewater. J Clean Prod [Internet]. 2019;208:1393-402. Available from: https://www.sciencedirect.com/science/article/pii/S0959652618331974

32. Villanueva-Rodríguez M, Bello-Mendoza R, Wareham DG, Ruiz-Ruiz EJ, Maya-Treviño M de L. Discoloration and organic matter removal from coffee wastewater by electrochemical advanced oxidation processes. Water, Air, Soil Pollut. 2014;225(12):1-11.

33. Moreira FC, Boaventura RAR, Brillas E, Vilar VJP. Electrochemical advanced oxidation processes: A review on their application to synthetic and real wastewaters. Appl Catal B Environ [Internet]. 2017;202:217-61. Available from: https://www.sciencedirect.com/science/article/pii/S0926337316306440

34. Flores N, Sirés I, Garrido JA, Centellas F, Rodríguez RM, Cabot PL, et al. Degradation of trans-ferulic acid in acidic aqueous medium by anodic oxidation, electro-Fenton and photoelectro-Fenton. J Hazard Mater [Internet]. 2016;319:3-12. Available from: https://www.sciencedirect.com/science/article/pii/S0304389415302405

35. Brillas E, Martínez-Huitle CA. Decontamination of wastewaters containing synthetic organic dyes by electrochemical methods. An updated review. Appl Catal B Environ [Internet]. 2015;166-167:603-43. Available from: https://www.sciencedirect.com/science/article/pii/S0926337314007176

36. Steter JR, Brillas E, Sirés I. On the selection of the anode material for the electrochemical removal of methylparaben from different aqueous media. Electrochim Acta [Internet]. 2016;222:1464-74. Available from: https://www.sciencedirect.com/science/article/pii/S0013468616324616

37. Komtchou S, Dirany A, Drogui P, Robert D, Lafrance P. Removal of atrazine and its by-products from water using electrochemical advanced oxidation processes. Water Res [Internet]. 2017;125:91-103. Available from: https://www.sciencedirect.com/science/article/pii/S004313541730698X

38. Thiam A, Salazar R. Fenton-based electrochemical degradation of metolachlor in aqueous solution by means of BDD and Pt electrodes: influencing factors and reaction pathways. Environ Sci Pollut Res [Internet]. 2019;26(3):2580-91. Available from: https://doi.org/10.1007/s11356-018-3768-2

39. Guelfi DR V, Ye Z, Gozzi F, de Oliveira SC, Machulek Junior A, Brillas E, et al. Ensuring the overall combustion of herbicide metribuzin by electrochemical advanced oxidation processes. Study of operation variables, kinetics and degradation routes. Sep Purif Technol [Internet]. 2019;211:637-45. Available from: https://www.sciencedirect.com/science/article/pii/S138358661833226X

40. Aveiro LR, Da Silva AGM, Candido EG, Antonin VS, Parreira LS, Papai R, et al. Application and stability of cathodes with manganese dioxide nanoflowers supported on Vulcan by Fenton systems for the degradation of RB5 azo dye. Chemosphere [Internet]. 2018;208:131-8. Available from: https://www.sciencedirect.com/science/article/pii/S0045653518309524

41. Fayazi M, Ghanei-Motlagh M. Electrochemical mineralization of methylene blue dye using electro-Fenton oxidation catalyzed by a novel sepiolite/pyrite nanocomposite. Int J Environ Sci Technol [Internet]. 2020;17(11):4541-8. Available from: https://doi.org/10.1007/s13762-020-02749-2

42. Babuponnusami A, Muthukumar K. Removal of phenol by heterogenous photo electro Fenton-like process using nano-zero valent iron. Sep Purif Technol. 2012;98:130-5.

43. Nidheesh PV, Gandhimathi R. Comparative Removal of Rhodamine B from Aqueous Solution by Electro-F enton and Electro-F enton-L ike Processes. CLEAN-Soil, Air, Water. 2014;42(6):779-84.

44. Brillas E. A review on the photoelectro-Fenton process as efficient electrochemical advanced oxidation for wastewater remediation. Treatment with UV light, sunlight, and coupling with conventional and other 
photo-assisted advanced technologies. Chemosphere [Internet]. 2020;250:126198. Available from: https://www.sciencedirect.com/science/article/pii/S004565352030391X

45. Gönder ZB, Kaya Y, Vergili I, Barlas H. Optimization of filtration conditions for CIP wastewater treatment by nanofiltration process using Taguchi approach. Sep Purif Technol. 2010;70(3):265-73.

46. Milkey KR, Samsudin AR, Dubey AK, Kidd P. Comparison between Taguchi Method and Response Surface Methodology (RSM) in Modelling CO 2 Laser Machining. Jordan J Mech Ind Eng. 2014;8(1).

47. D1252-06 A. Standard Test Methods for Chemical Oxygen Demand (Dichromate Oxygen Demand) of Water. ASTM, International West Conshohocken, PA; 2006.

48. Oh S-Y, Chiu PC, Kim BJ, Cha DK. Zero-valent iron pretreatment for enhancing the biodegradability of RDX. Water Res. 2005;39(20):5027-32.

49. Coelho A, Castro A V, Dezotti M, Sant'Anna Jr GL. Treatment of petroleum refinery sourwater by advanced oxidation processes. J Hazard Mater. 2006;137(1):178-84.

50. Byrappa K, Dayananda AS, Sajan CP, Basavalingu B, Shayan MB, Soga K, et al. Hydrothermal preparation of ZnO: CNT and TiO 2: CNT composites and their photocatalytic applications. J Mater Sci. 2008;43(7):2348-55.

51. Tony MA, Purcell PJ, Zhao YQ, Tayeb AM, El-Sherbiny MF. Photo-catalytic degradation of an oil-water emulsion using the photo-fenton treatment process: Effects and statistical optimization. J Environ Sci Heal Part A. 2009;44(2):179-87.

52. Xing Z, Sun D, Yu X. Treatment of antibiotic fermentation wastewater using the combined polyferric sulfate coagulation with Fenton-like oxidation. Environ Prog Sustain Energy. 2010;29(1):42-51.

53. Tambosi JL, Di Domenico M, Schirmer WN, José HJ, Moreira R de FPM. Treatment of paper and pulp wastewater and removal of odorous compounds by a Fenton-like process at the pilot scale. J Chem Technol Biotechnol Int Res Process Environ Clean Technol. 2006;81(8):1426-32.

54. Dehghani M, Shahsavani E, Farzadkia M, Samaei MR. Optimizing photo-Fenton like process for the removal of diesel fuel from the aqueous phase. J Environ Heal Sci Eng. 2014;12(1):1-7.

55. Chiou C-S, Chang C-F, Chang C-T, Shie J-L, Chen Y-H. Mineralization of Reactive Black 5 in aqueous solution by basic oxygen furnace slag in the presence of hydrogen peroxide. Chemosphere. 2006;62(5):78895.

56. Kallel M, Belaid C, Mechichi T, Ksibi M, Elleuch B. Removal of organic load and phenolic compounds from olive mill wastewater by Fenton oxidation with zero-valent iron. Chem Eng J. 2009;150(2-3):391-5.

57. Kuo WG. Decolorizing dye wastewater with Fenton's reagent. Water Res. 1992;26(7):881-6.

58. Flores N, Brillas E, Centellas F, Rodríguez RM, Cabot PL, Garrido JA, et al. Treatment of olive oil mill wastewater by single electrocoagulation with different electrodes and sequential electrocoagulation/electrochemical Fenton-based processes. J Hazard Mater [Internet]. 2018;347:58-66. Available from: https://www.sciencedirect.com/science/article/pii/S0304389417309597

59. Mousset E, Huang Weiqi V, Foong Yang Kai B, Koh JS, Tng JW, Wang Z, et al. A new 3D-printed photoelectrocatalytic reactor combining the benefits of a transparent electrode and the Fenton reaction for advanced wastewater treatment. J Mater Chem A [Internet]. 2017;5(47):24951-64. Available from: http://dx.doi.org/10.1039/C7TA08182K

60. Khataee AR, Zarei M. Photocatalysis of a dye solution using immobilized ZnO nanoparticles combined with photoelectrochemical process. Desalination. 2011;273(2-3):453-60.

61. Khataee AR, Zarei M, Asl SK. Photocatalytic treatment of a dye solution using immobilized TiO2 nanoparticles combined with photoelectro-Fenton process: Optimization of operational parameters. J Electroanal Chem [Internet]. 2010;648(2):143-50. Available from: 
https://www.sciencedirect.com/science/article/pii/S1572665710003309

62. Oriol R, Sirés I, Brillas E, De Andrade AR. A hybrid photoelectrocatalytic/photoelectro-Fenton treatment of Indigo Carmine in acidic aqueous solution using $\mathrm{TiO} 2$ nanotube arrays as photoanode. J Electroanal Chem. 2019;847:113088.

63. Zhang L, Cheng H, Zong R, Zhu Y. Photocorrosion suppression of ZnO nanoparticles via hybridization with graphite-like carbon and enhanced photocatalytic activity. J Phys Chem C. 2009;113(6):2368-74.

64. Coronado JM, Fresno F, Hernández-Alonso MD, Portela R. Design of advanced photocatalytic materials for energy and environmental applications. Springer; 2013.

65. Heidari B, Soleimani M, Mirghaffari N. The use of steel slags in the heterogeneous Fenton process for decreasing the chemical oxygen demand of oil refinery wastewater. Water Sci Technol. 2018;78(5):115967.

66. Li Y-S, You Y-H, Lien E-T. Oxidation of 2, 4-dinitrophenol by hydrogen peroxide in the presence of basic oxygen furnace slag. Arch Environ Contam Toxicol. 1999;37(4):427-33.

67. Ali MEM, Gad-Allah TA, Badawy MI. Heterogeneous Fenton process using steel industry wastes for methyl orange degradation. Appl Water Sci. 2013;3(1):263-70.

68. Nasuha N, Ismail S, Hameed BH. Activated electric arc furnace slag as an efficient and reusable heterogeneous Fenton-like catalyst for the degradation of Reactive Black 5. J Taiwan Inst Chem Eng. 2016;67:235-43.

69. BAYAT BKR, EBRAHIMI M, KEYVANI B. Removal of Acid red 206 Dye in Pollutant Water by ZnFe2O4/Bentonite as a Nanophotocatalyst in Batch Reactor Using Taguachi Method. 2013;

70. Ifelebuegu AO, Ezenwa CP. Removal of endocrine disrupting chemicals in wastewater treatment by Fentonlike oxidation. Water, Air, Soil Pollut. 2011;217(1-4):213-20.

71. Chavoshani A, Amin MM, Asgari G, Seidmohammadi A, Hashemi M. Microwave/hydrogen peroxide processes. In: Advanced Oxidation Processes for Waste Water Treatment. Elsevier; 2018. p. $215-55$.

72. Takeuchi M, Hidaka M, Anpo M. Efficient removal of toluene and benzene in gas phase by the TiO2/Yzeolite hybrid photocatalyst. J Hazard Mater [Internet]. 2012;237-238:133-9. Available from: http://dx.doi.org/10.1016/j.jhazmat.2012.08.011

73. Ganiyu SO, Zhou M, Martínez-Huitle CA. Heterogeneous electro-Fenton and photoelectro-Fenton processes: A critical review of fundamental principles and application for water/wastewater treatment. Appl Catal B Environ [Internet]. 2018;235:103-29. Available from: https://www.sciencedirect.com/science/article/pii/S0926337318303734

74. Nidheesh P V, Zhou M, Oturan MA. An overview on the removal of synthetic dyes from water by electrochemical advanced oxidation processes. Chemosphere [Internet]. 2018;197:210-27. Available from: https://www.sciencedirect.com/science/article/pii/S0045653517321732 